\title{
Estudo sobre práticas de cuidado em saúde mental na Atenção Primária: o caso de um município do interior do estado do Rio de Janeiro
}

\author{
Study on mental health care practices in the primary care: \\ the case of a municipality in the state of Rio de Janeiro
}

\author{
Ailson Campos Junior ${ }^{1}$, Paulo Duarte de Carvalho Amarante
}

\begin{abstract}
Resumo
Objetivo: O objetivo deste estudo foi compreender/problematizar como eram realizadas as abordagens que surgiam como demandas em saúde mental na prática do médico nessas unidades de saúde. Desse modo, a prática dos profissionais médicos que assistem os usuários da Estratégia de Saúde da Família, a relação com as questões de saúde mental, a capacidade de uma visão mais holística da comunidade assistida e a relação com o uso de medicações psicofarmacológicas foram as três categorias analíticas que balizaram a realização da pesquisa em todas as suas fases. Método: Foram realizadas entrevistas semiestruturadas com os profissionais médicos e o material coletado foi analisado pela técnica de análise do discurso. Os textos foram lidos exaustivamente e decompostos em fragmentos que foram agrupados por temas coincidentes com as intenções e objetivos a que o estudo se orienta Resultado: Foi compreendido, dentre outras coisas, que a relação que os médicos assumem com a comunidade assistida de maneira geral ainda está muito atrelada a uma visão clínica-institucional que não privilegia algumas questões de identidade, cultura e movimentos sociais nas comunidades. Também foi observada a inexistência de práticas voltadas para o empoderamento dos sujeitos sobre suas condições de vida, saúde e subjetividade.
\end{abstract}

Palavras-chave: Práticas de saúde; saúde mental; atenção primária.

\begin{abstract}
Objective: This study aimed to understand/discuss the development of approaches that emerged as demands on mental health in the physician practice in these health facilities. The research was guided by three analytical categories comprised by: the practice of medical professionals who assist users of the Family Health Strategy; the relationship with mental health issues, the ability of a more holistic view of the community attended and the relationship with the use of psychopharmacological drugs. Methods: We conducted semi-structured interviews with medical professionals and the data collected was analyzed using discourse analysis. The texts were read thoroughly and broken down into fragments that were grouped by themes matching the study intentions and objectives Result: The study showed, among others, that the relationship doctors-assisted community in general is still connected to a clinic-institutional vision that does not favor some issues of identity, culture and social movements in the communities. We noted the lack of practices aimed at the empowerment of the subjects on their living conditions, health and subjectivity.
\end{abstract}

Keywords: Health Practices; mental health; primary care.

${ }^{1}$ Escola Nacional de Saúde Pública (ENSP), Fundação Oswaldo Cruz (FIOCRUZ) - Rio de Janeiro, RJ, Brasil.

Trabalho realizado na Escola Nacional de Saúde Pública (ENSP), Fundação Oswaldo Cruz (Fiocruz) - Rio de Janeiro (RJ), Brasil.

Endereço para correspondência: Ailson Campos Junior - Rua Fernando Teixeira, 59 - Tuim - CEP: 28680-000 - Cachoeiras de Macacu (RJ), Brasil -

Email: juninhopsi10@yahoo.com.br

Fonte de financiamento: nenhuma.

Conflito de interesses: nada a declarar. 


\section{INTRODUÇÃO}

A expansão da Estratégia de Saúde da Família (ESF) tem favorecido a equidade e universalidade da assistência - uma vez que as equipes têm sido implantadas, prioritariamente, em comunidades antes restritas ao acesso aos serviços de saúde. Entretanto, não se pode admitir, só pelas estatísticas, que a integralidade das ações deixou de ser um problema na prestação da atenção.

A ESF, desde 2000, passou a ser considerada pelo Ministério da Saúde como uma estratégia estruturante dos sistemas municipais de saúde, com vistas a reorientar o modelo assistencial e imprimir uma nova dinâmica na organização dos serviços e ações de saúde ${ }^{1}$.

A proposta da ESF prevê a participação de toda a comunidade, em parceria com a Equipe de Saúde da Família, na identificação das causas dos problemas de saúde, na definição de prioridades, no acompanhamento da avaliação de todo trabalho.

A Estratégia de Saúde da Família foi pensada como alternativa ao modelo biomédico e concebida como um instrumento de reorganização do SUS e da municipalização. A primeira publicação federal sobre o Saúde da Família definiu que seus objetivos seriam a reorganização da prática assistencial em novas bases e critérios, em substituição ao modelo tradicional de assistência, orientado para a cura de doenças no hospital. A atenção estaria, dessa forma, centrada na família, entendida e percebida a partir do seu ambiente físico e social, o que vem possibilitando às equipes de Saúde da Família uma compreensão ampliada do processo saúde/doença e da necessidade de intervenções que vão além de práticas curativas ${ }^{2,3}$.

Segundo orientações do Ministério da Saúde, na ESF, as ações são estruturadas no trabalho em equipe e buscam humanizar as práticas de saúde, com o objetivo de obter a satisfação do usuário através do estreito relacionamento dos profissionais com a comunidade. O processo de trabalho das equipes se estrutura a partir do conceito de delimitação do território, mapeamento das áreas e microáreas, a primeira entendida como um conjunto de microáreas contíguas sob a responsabilidade de uma equipe, onde residam em torno de 3 mil a 4.500 pessoas e a segunda como área de atuação de um agente comunitário de saúde, em que morem cerca de 400 a 750 pessoas, com cadastramento familiar e utilização do Sistema de Informação de Atenção Básica (SIAB) ${ }^{4}$.

Pelos idos de 1970 e 1980, a Organização Mundial da Saúde $(\mathrm{OMS})^{5}$ já reconhecia a magnitude dos problemas de saúde mental e admitia a impossibilidade de seu cuidado ficar a cargo exclusivo de especialistas. Sendo assim, preconizou então, dentre outras coisas, a descentralização dos serviços existentes, a integração de serviços psiquiátricos em unidades de cuidados gerais, a formação de cuidadores não especializados e o aumento da participação da comunidade.
Aqui no Brasil, essas ideias passaram a ser incorporadas e veiculadas pelo movimento da Reforma Psiquiátrica Brasileira, que nasceu no eco da Reforma Sanitária, tendo mantido princípios e diretrizes que orientaram essa última, em especial universalidade, integralidade, descentralização e participação popular6.

Para tanto, fazem-se necessárias análises qualitativas da ESF em desenvolvimento nos municípios brasileiros, particularmente quanto às práticas de saúde e aos processos de trabalho cotidianos.

Esse fato torna a questão da qualidade da atenção em saúde mental um tema candente e urgente para a Saúde Coletiva, para a educação permanente dos profissionais de saúde e para sua atuação cotidiana, particularmente para as equipes da ESF (e para toda a rede primária).

Segundo o Ministério de Saúde ${ }^{6}$, um dos principais desafios da Reforma Psiquiátrica é que 3\% da população necessitam de cuidados contínuos em saúde mental, em função de transtornos severos e persistentes, o que exige uma rede de assistência densa, diversificada e efetiva. Somado a isso, aproximadamente de $10 \%$ a $12 \%$ da população não sofrem transtornos severos mas precisam de cuidados em saúde mental, na forma de consulta médico-psicológica, aconselhamento, grupos de orientação e outras formas de abordagem. Isso, consequentemente demanda uma rede assistencial ampla e integrada. Além disso, a Organização Mundial da Saúde (OMS) vem registrando uma preocupação gradativa nos últimos anos com as chamadas doenças crônicas, no mundo inteiro, dentre as quais estão os transtornos mentais. Os problemas de saúde mental ocupam cinco posições no ranking das 10 principais causas de incapacidade no mundo, totalizando $12 \%$ da carga global de doenças. Segundo a OMS, atualmente, mais de 400 milhões de pessoas são acometidas por distúrbios mentais ou comportamentais e, em virtude do envelhecimento populacional e do agravamento dos problemas sociais, há probabilidade de o número de diagnósticos ser ainda maior. Esse progressivo aumento na carga de doenças irá gerar um custo substancial em termos de sofrimento, incapacidade e perda econômica ${ }^{7}$.

Aliado a isto, há evidências da alta prevalência de demanda em saúde mental na Atenção Primária no Brasil dentre a população atendida, caracterizada em grande parte por casos de quadros depressivos e ansioso-leves, TMC - transtorno mental comum, assim como preocupações, irritabilidade e múltiplos sintomas psicossomáticos ${ }^{8}$.

Ainda segundo dados desse relatório, a depressão está para se tornar a segunda principal causa de incapacidade em todo o mundo, pois afeta de $5 \%$ a $10 \%$ da população e é a terceira razão mais comum para consulta na Atenção Primária à Saúde.

A Estratégia de Saúde da Família no município estudado conta com 9 equipes de saúde, que perfazem cerca de $36 \%$ da 
cobertura municipal, abrangendo cuidados a cerca de 6 mil famílias.

A ESF foi implantada no município de Cachoeiras de Macacu em 2002 e, como nos demais municípios brasileiros, fez jus à ineficácia do modelo tradicional, que se apresentava com baixa resolutividade e difícil acesso, gerando insatisfação dos usuários e mantendo um quadro nosológico insatisfatório. Acreditava-se que através da abordagem multiprofissional, englobando práticas preventivas e de promoção da saúde, pautadas na vigilância da saúde, fosse possível contribuir positivamente para a qualidade de vida da população. Atualmente, a APS do município conta com três ESFs na zona urbana e seis na zona rural.

As demandas surgidas em saúde mental na atenção básica municipal são, em sua grande maioria, referenciadas para o CAPS e ou atenção ambulatorial especializada, numa relação que privilegia o sistema de referência/contrarreferência.

De acordo com o censo do IBGE 2010'. Cachoeiras de Macacu tem uma população de 56.529 habitantes, com 84,7\% residindo na zona urbana, na proporção de 101,4 homens para cada 100 mulheres. A densidade demográfica é de 53 habitantes por $\mathrm{km}^{2}$. A população municipal experimenta uma taxa de crescimento maior que a média estadual.

A maioria da população ativa trabalha em comércio e serviços que, de certa forma, só atendem a população local. Outro grande empregador é a prefeitura municipal. Hoje a média de renda da cidade gira em torno e 1,5 salário-mínimo. O setor de serviços é o maior empregador formal do município, com $36 \%$ dos postos formais de trabalho, seguido pela administração pública, com $18 \%$ das ocupações formais, pelo comércio, com $16,3 \%$ das ocupações formais, pela indústria, com 15,7\%, e pela agropecuária, com 10,2\% das ocupações formais ${ }^{10}$.

Atualmente, o município possui uma rede de saúde composta por um hospital geral, sete unidades básicas de saúde, um Centro de Atenção Psicossocial (CAPS), um ambulatório de saúde mental, um ambulatório de especialidades, nove unidades de Estratégia Saúde da Família (ESF), uma unidade de vigilância sanitária e uma unidade de vigilância epidemiológica.

A relação da Estratégia Saúde da Família com as Unidades Básicas tradicionais se dá através dos encaminhamentos às especialidades.

Vale ressaltar que seis das nove unidades de saúde da família estão alocadas no interior do município. A faixa territorial do município é bastante extensa e o transporte público apresenta sérias fragilidades sendo, às vezes, até inexiste em alguns distritos. Esse fator prejudica muito a complementariedade da rede de cuidado entre a ESF e os demais serviços de saúde dispostos no município. A relação das ESF com a rede ocorre por meio de guias de referência.

A Atenção Primária do município, reconhecida como a porta de entrada preferencial da população na Rede de Serviços de
Saúde, conta atualmente com nove ESF que contam com 47 ACS - Agentes Comunitários de Saúde, os quais desenvolvem um leque de ações, tendo como um de seus pilares a humanização da assistência e a busca da atenção integral aos indivíduos e comunidade, sendo responsáveis por uma cobertura aproximada de 36\% dos habitantes. A assistência aos usuários de Saúde Mental está inserida na rede segundo o modelo de gestão preconizado pelo município. Esse modelo privilegia que a atenção ao usuário deve ser realizada por toda equipe de saúde das Estratégias de Saúde da Família e que isso deverá ser realizado, dentre outras formas, através de visitas domiciliares mensais regulares, orientações e consultas ${ }^{11}$.

Foi com esse olhar que se deu a aproximação com essa realidade rica de relações complexas, contradições e desafios no cuidado direcionado ao usuário da Estratégia de Saúde da Família. Na análise do objeto, consideraram-se as mudanças significativas vivenciadas na atualidade pela assistência médica, que vislumbram e descortinam possibilidades na otimização do cuidado oferecido a esse usuário.

\section{MÉTODO}

Este estudo baseia-se em uma pesquisa de campo qualitativa, do tipo exploratório-descritiva.

O instrumento utilizado para coleta das entrevistas foi um roteiro semiestruturado (Anexo A).

A entrevista semiestruturada procura evitar a rigidez do questionário para melhor apreender o ponto de vista dos atores sociais. O roteiro foi concebido como um guia e não como uma amarra, permitindo ao entrevistador introduzir novas reflexões que possam contribuir para o esclarecimento ou aprofundamento das informações que estão sendo colhidas ${ }^{12}$.

Cumpre sinalizar que como este estudo não apresentou nenhum instrumento específico de coleta dos dados, seus resultados necessitam de uma avaliação cautelosa e contextualizada no nível local. Assim sendo, uma das limitações deste estudo consiste em restrições na extrapolação de seus resultados.

Assumiu-se que o método desta pesquisa está diretamente relacionado aos significados que os atores sociais atribuem a suas experiências no mundo social e ao modo como eles compreendem esse mundo. Dessa forma, buscou-se, aqui, investigar e interpretar os fenômenos sociais em termos dos sentidos que as pessoas lhes dão, sem se preocupar em quantificar mas, sim, em compreender e explicar a dinâmica das relações sociais.

A definição dos sujeitos da pesquisa não foi sustentada por critério numérico, porém procurou-se garantir a representatividade das circunstâncias nas quais se apresentou a realidade do fenômeno, na realidade concreta, balizada na geografia do município, na qual foram privilegiadas as características urbanas e rurais e do pensar e fazer saúde. Foram entrevistados os médicos de 
três unidades sediadas no ambiente urbano e quatro outros médicos que trabalhavam em unidades rurais no município.

Para o início da coleta de dados foram elaboradas listas das unidades a serem visitadas e nesse momento privilegiaram-se quatro unidades de saúde da família localizadas no meio rural do município e outras três unidades do espaço urbano também relacionadas. Procurou-se obter com essa escolha uma homogeneidade das equipes a serem estudadas, dada sua localização no território em questão. Foram privilegiadas questões como dificuldades na mobilidade dos usuários, equipes compostas por médicos que disponibilizavam uma carga horária de trabalho semanal similar e ainda acessibilidade ao profissional entrevistado.

O total de sete entrevistas foi considerado suficiente para elucidar momentaneamente o fenômeno em estudo, ou seja, obedecido o critério de saturação dos dados, como é próprio dos estudos qualitativos.

Quanto ao sexo, foram estudados seis homens e uma mulher. As idades variaram entre 27 e 63 anos, o que nos sugere que as equipes são compostas ora por profissionais jovens e em início de carreira e ora por profissionais com idade mais avançada e com um percurso profissional mais extenso. Além disso, nenhum deles tinha se formado havia menos de um ano; três tinham entre um e cinco anos de formados; dois, entre 6 e 10 anos; e dois haviam se formado há mais de 10 anos. Três médicos trabalhavam entre um e dois anos e quatro médicos trabalhavam havia mais de 4 anos na ESF.

Quanto ao tipo de contrato de trabalho, foi constatado que a inserção na ESF aconteceu para todos após processo de análise de currículo. Salvo a exceção de um profissional que recentemente passou a pertencer ao município a partir da iniciativa do PROVAB ${ }^{1}$.

Na seleção realizada pela Secretaria de Saúde para contratação dos médicos não foi exigida residência médica em medicina geral e comunitária ou em medicina de família e comunidade. Todos foram contratados por meio de um contrato de prestação de serviço (CLT ${ }^{2}$ - renovável de dois em dois anos). Esse formato apresenta, em seu conjunto, um retrato preocupante da precarização

\footnotetext{
PROVAB é um programa de valorização da atenção básica recentemente criado pelo governo federal. Esse programa estimula atuação de profissionais na atenção básica em periferias de grandes cidades, municípios do interior ou em áreas mais remotas. Médicos bem avaliados receberão bônus de $10 \%$ em provas de residência. O programa valoriza profissionais que atuarem durante 12 meses em periferias de grandes cidades, municípios do interior ou em áreas mais remotas, como Amazônia Legal Brasileira, semiárido nordestino, área de população e atuação indígenas.

b A CLT surgiu pelo decreto-lei n. 5.452, de $1^{\circ}$ de maio de 1943, sancionada pelo então presidente Getúlio Vargas, unificando toda legislação trabalhista existente no Brasil. Seu principal objetivo é a regulamentação das relações individuais e coletivas do trabalho nela previstas. A CLT é o resultado de 13 anos de trabalho - desde o início do Estado Novo até 1943 - de destacados juristas que se empenharam em criar uma legislação trabalhista que atendesse à necessidade de proteção do trabalhador, dentro de um contexto de "estado regulamentador".
}

da força de trabalho dedicada à ESF, como apontado em um estudo que constatou quadro semelhante em outros municípios.

Quanto às especializações dos médicos foram citadas como residência médica: Anestesiologia, Pediatria, Clínica Médica Geral, Nefrologia, Medicina do Trabalho. Três entrevistados ainda não fizeram residência médica. Cabe ressaltar que, como a ESF é recente, a maior parte dos entrevistados se graduou antes da sua criação. Três profissionais possuem mais de uma especialização. Vale ressaltar que nenhum profissional entrevistado relatou ter especialização em Medicina de Família.

Na medida em que o objeto deste estudo é voltado para análise do conhecimento das práticas de cuidado realizadas pelo profissional médico, inclusive por esse profissional ser o único amparado legalmente a prescrever medicamentos psicotrópicos, os demais profissionais da ESF não foram entrevistados. A exclusividade desse profissional traz consigo a intenção de perceber, diante do cenário estudado, como se desenvolvem as possibilidades terapêuticas propostas por ele no campo da saúde mental. Este estudo, dentre outras coisas, traz como objetivo analisar as diversas possibilidades de intervenção na atuação desse profissional e/ou o enrijecimento dos processos de medicalização. Outro fator preponderante nessa escolha foi a constatação de que cerca de $70 \%$ das demandas surgidas nas unidades recebem a consulta médica como uma das etapas de atenção ${ }^{13}$.

Neste estudo, a definição dos sujeitos e dos critérios de acesso a eles e de sua inclusão na pesquisa tiveram como referência a orientação de que numa busca qualitativa preocupamo-nos menos com a generalização e mais com o aprofundamento e abrangência da compreensão, seja de um grupo social, de uma organização, de uma instituição, de uma política ou de uma representação ${ }^{14}$.

O material produzido por esse tipo de entrevista tende a ser muito mais denso e profundo do que o produzido por questionários, permitindo a captação do universo afetivo-existêncial do sujeito, que outros métodos mais impositivos são incapazes de suscitar. Assim, costuma-se deixar de lado a preocupação com a "objetividade" do entrevistador, no sentido do seu não envolvimento, do uso cuidadoso de uma linguagem precisa, do controle rígido de atitudes corporais, fisionômicos, de gestos, frases e palavras. Nesse tipo de pesquisa, o envolvimento do entrevistador com o entrevistado torna-se condição de aprofundamento de uma relação intersubjetiva, essencial para o êxito da pesquisa, já que é justamente o nível afetivo existencial aquele que mais determina os comportamentos.

Cumpre lembrar que apesar de as entrevistas balizarem-se por roteiro de questões disparadoras (Anexo A), foi comum perceber que os caminhos assumidos durante elas assumiram características diversas: a análise do material obtido procurou privilegiar através das categorias de análise a amplitude das questões colocadas. 
Antes de iniciarem-se as entrevistas, o pesquisador procurou estabelecer uma relação de confiança mútua com o entrevistado, na busca de propiciar um clima de afinidade, simpatia e lealdade, com o propósito de obter sua participação ativa, como também a profundidade nas respostas às questões sobre o fenômeno em estudo. As entrevistas foram realizadas no período compreendido entre 10 de fevereiro e 28 de março de 2013. Para resguardar a integridade dos discursos, utilizou-se como recurso o gravador, sempre com a anuência do entrevistado, no sentido de garantir a fidedignidade das informações. Uma vez gravado, o conteúdo das entrevistas foi transcrito pelo pesquisador.

A primeira leitura de cada entrevista foi realizada, logo após a coleta, com olhar atento, na busca de apreender os significados globais do texto e captar o momento em que os discursos começassem a ser repetitivos. Considerada a saturação dos discursos com a repetição de temas, foi interrompida a coleta de dados e procederam-se novas leituras na íntegra de cada discurso, sem a preocupação de interpretar. Partindo-se de alguns pontos de interesse da pesquisa que ao mesmo tempo nortearam o pesquisador, chegou-se a alguns dados conclusivos e relevantes sobre algumas práticas de cuidados oferecidas aos usuários da Saúde Família no território pesquisado.O material foi analisado pela técnica de análise do discurso, para a qual o texto é uma produção material que permite a identificação das visões de mundo dos sujeitos. Os textos foram lidos exaustivamente e decompostos em fragmentos que foram agrupados por temas coincidentes e inseridos em uma análise qualitativa contemplando três categorias, com as intenções e objetivos que orientaram o estudo ${ }^{14}$.

Um último processo de reinterpretação foi realizado após a etapa da análise dos conteúdos. Nessa etapa realizou-se uma construção-síntese fundamentada na reinterpretação dos dados empíricos, mediante diálogo conceitual com autores que tratam da temática estudada e análise da conjuntura, num contínuo movimento dialético ${ }^{15}$.

Na pesquisa a que se refere este estudo, o trabalho de campo foi interrompido quando se avaliou que com o material obtido seria possível: 1) identificar padrões simbólicos e práticas empregadas no universo estudado; 2) descrever e analisar diferentes trajetórias profissionais e construir hipóteses relativas ao processo de formação e de socialização profissional; 3) identificar valores, concepções, ideias, referenciais simbólicos que organizam as relações no interior desse meio profissional, buscando compreender seus códigos; 4) configurar algum nível de generalização no que diz respeito a essa categoria profissional, ao seu sistema de aprendizagem, regras de funcionamento, relação com o trabalho, rituais de ingresso, de consagração e assim por diante.

O projeto de pesquisa foi encaminhado ao Comitê de Ética em Pesquisa CEP-FIOCRUZ em 3-12-2012. Analisado sob o aspecto ético-legal, atendeu à Resolução 196/96 do Conselho
Nacional de Saúde, que regulamenta a pesquisa com seres vivos. O projeto foi aprovado em 5-2-2013 sob o número CAAE 10887312.4.0000.5240.

Foram selecionadas como eixo de análise estruturante as seguintes categorias de análise:

1) A práxis dos entrevistados: A rede de cuidado em saúde mental no território

Nessa categoria buscou-se avaliar, a partir de questões disparadoras, o entendimento e a significação que o entrevistado atribui ao tema saúde mental e as diversas formas que essa subjetivação assume em suas práticas de cuidado. A escolha das questões disparadoras foi motivada pelo interesse em apreender através da livre associação de ideias qual ou quais seriam os significados que os sujeitos atribuiriam às questões de saúde mental na atenção básica.

Conte-me sobre sua trajetória profissional em relação a saúde mental...

Como você vê as questões da saúde mental no município?

2) A dimensão dada ao tratamento psicofarmacológico

Quando se avalia a trajetória do tratamento para o doente mental na organização do SUS, constata-se que, até bem pouco tempo, esse não era realizado pelos profissionais da atenção básica. Muitos casos considerados graves nem constavam nos registros populacionais da ESF, enquanto os casos mais leves eram sistematicamente encaminhados para os ambulatórios especializados, restringindo-se o atendimento apenas à repetição das receitas prescritas pelos psiquiatras ${ }^{16}$.

A análise dessa categoria traz como intenção perceber como se desenvolve a relação dos entrevistados com a prescrição e/ou transcrição de receitas de medicações psicotrópicas. Levando em consideração que a ESF constitui a porta de entrada para muitos usuários no SUS, a análise dessa categoria nos permite identificar a relação que os médicos entrevistados mantêm com as prescrições de psicotrópicos nesse espaço de atenção à saúde.

Como você avalia a rede de atenção em saúde mental aqui no município?

Fale um pouco sobre sua conduta diante das demandas em saúde mental...

3) A atenção psicossocial na Estratégia de Saúde da Família em conformidade com os aspectos da Reforma Psiquiátrica.

Você conhece alguma atividade terapêutica na comunidade? Fale sobre elas...

Como você avalia a rede de atenção em saúde mental aqui no município?

Fale um pouco sobre sua conduta diante das demandas em saúde mental...

A ESF propõe como diretriz o desenvolvimento do trabalho tendo por base relações de cooperação, em equipe, que integralizam 
as ações e complementam o processo de produção utilizando tecnologias básicas e recursos encontrados muitas vezes na próprio arranjo organizacional da comunidade. A organização e a divisão desse processo definem-se pelo objetivo final que se quer atingir, uma assistência à população de forma humanizada.

A lógica da organização e divisão do trabalho em saúde, no Brasil, situa-se nos dois modelos de assistência, o médico-curativo e o de promoção da saúde. Embora o PSF tenha surgido como estratégia de mudança do antigo modelo (meramente curativo), essa herança ainda persiste no processo de trabalho e na percepção popular, o que leva a uma série de problemas para ambas as partes. A comunidade ainda tem dificuldade de entender o funcionamento do programa e a rotina de trabalho, até porque não participou efetivamente do processo de implantação. A população sente-se no direito de ter seus "direitos" atendidos, independentemente da qualidade da assistência prestada, por não ter assimilado ainda a nova proposta de trabalho.

A partir dos avanços da Reforma Psiquiátrica, criou-se uma responsabilidade pelo delineamento de novos caminhos na assistência aos usuários. A reforma propõe-se a romper gradativamente com o modelo centrado no hospital, a criar serviços territoriais abertos. Surge, então, a necessidade de articular saúde mental e ESF, trazendo mais uma demanda para os profissionais que atuam nessas áreas.

Sendo assim, um dos objetivos desta pesquisa foi avaliar como os profissionais médicos entrevistados entendiam e miravam suas práticas para que a população atendida de fato pudesse experimentar alguns dos pressupostos da Reforma Psiquiátrica no Brasil.

Uma das questões disparadoras da entrevista trazia como temática de reflexão o conhecimento que os entrevistados possuíam sobre as $\mathrm{ATs}^{3}$ (atividades terapêuticas) desenvolvidas na comunidade. Ao formular a questão disparadora eram feitas referências ao fato de o entrevistado conhecer na comunidade movimentos sociais, grupos de terceira idade, ONGs, associação de moradores, grupos de autoajuda, grupos de idosos, espaços de escuta, apoio, rodas de conversa ou outros. Essa indagação traz a intenção de perceber o quanto esse profissional conhece sobre o seu território de atuação.

\section{RESULTADOS}

A práxis dos entrevistados: A rede de cuidado em saúde mental no território

O trabalho cotidiano dos médicos entrevistados neste estudo consiste quase que exclusivamente em consultas clínicas na unidade, em detrimento de visitas domiciliares, reuniões

\footnotetext{
ATs - Tomamos como conceito de atividades terapêuticas aquelas que existindo na comunidade ampliariam o escopo de atenção ao bem-estar psicossocioafetivo dos sujeitos. São atividades com complexo nível de variação, podendo incluir diversas orientações e objetivos: (manifestações religiosas; esportivas; artísticas; de lazer; culturais; reabilitadoras; terapêuticas; políticas etc.).
}

semanais com a equipe e campanhas educativas, conforme preconizado pelo Ministério da Saúde ${ }^{17}$.

Com relação à questão da formação dos médicos que hoje compõem as equipes do município estudado vale salientar que nenhum dos profissionais entrevistados relatou ter especialização em Saúde da Família. Em sua maioria, os médicos entrevistados fizeram menção exclusivamente a suas especialidades clínicas e ao trabalho realizado na unidade, com referências muito esparsas às abordagens que realizam nos diversos contextos das comunidades, ou seja, privilegiaram os atendimentos realizadas apenas no consultório médico. Sendo assim, as consultas médicas foram citadas como a principal atividade do médico, que deve atender, segundo normatização da Secretaria Municipal, pessoas de todas as faixas etárias e gêneros (crianças, adultos, idosos e gestantes), numa sistemática de horários que intercala pacientes agendados com a demanda eventual. A ESF surge com o propósito de reorganizar a atenção básica no SUS, tendo como princípios gerais a universalidade, a integralidade, o enfoque na prevenção, na família, população adscrita, participação comunitária e controle social, através da formação de uma equipe multiprofissional na qual cada um tem seu papel ímpar e que juntos trabalham para dar melhor assistência e garantir que os usuários tenham seus direitos assegurados ${ }^{6}$.

Outro fator que também merece ser analisado diz respeito à falta de sinalização nas entrevistas ao quesito das discussões de casos junto à equipe. Não foi possível identificar em nenhum dos relatos uma fala que privilegiasse algum caso clínico que pudesse ser, ou que fora, discutido e analisado juntamente com toda a equipe da ESF. De acordo com Merhy, é preciso potencializar o espaço da Atenção Primária á saúde aguçando em todos os profissionais imersos nesse dispositivo um olhar mais ampliado acerca das realidades atravessadas pela comunidade ${ }^{18}$.

A investigação da articulação técnica e da interação entre os profissionais de equipes da ESF no Brasil demonstra que são pouco referidas situações em que se exercita a discussão crítica em torno dos problemas e necessidades da equipe e da população na busca de consensos coletivos ${ }^{19}$.

Apenas dois médicos entrevistados fizeram menção espontânea à estrutura e dinâmica familiares. Nos outros discursos, a família deixou de ser considerada como unidade de atenção e cuidado, sendo os indivíduos o foco da atenção clínica.

Vale destacar que é na família que encontramos os primeiros "outros" e com eles aprendemos o modo humano de existir. Alí, na família, ou nas relações com próximos, é que o mundo adquire significado e começamos a nos constituir como sujeitos.

Isso se dá na e pela troca intersubjetiva, construída na afetividade, e constitui o primeiro referencial para a nossa constituição identitária. Ao nascermos, já encontramos um mundo organizado, segundo parâmetros construídos pela sociedade como um todo e assimilados idiossincraticamente pela 
família que, por sua vez, também carrega uma cultura própria. Essa cultura familiar que é específica apresenta-se impregnada de valores, hábitos, mitos, pressupostos, formas de sentir e de interpretar o mundo que definem diferentes maneiras de trocas intersubjetivas e, consequentemente, tendências na constituição da subjetividade ${ }^{20}$.

É de suma importância que o profissional da Equipe de Saúde da Família se integre com a comunidade para compreender seu papel psicossocial e espiritual, buscando interpretar a realidade vivida por cada integrante, seja individual ou coletivamente, para que possa direcioná-los para uma vida saudável através do empoderamento de suas ações de promoção em saúde.

A proposta da ESF prevê a participação de toda a comunidade, em parceria com a Equipe de Saúde da Família, na identificação das causas dos problemas de saúde, na definição de prioridades, no acompanhamento da avaliação de todo o trabalho. Isso é importante para que as pessoas adquiram consciência de que podem tomar a iniciativa, como sujeitos capazes de elaborar projetos próprios de desenvolvimento, tanto em nível individual como coletivo ${ }^{21}$.

Merece atenção a referência ao fato de o curso de graduação em Medicina não ter dado destaque e capacitação aos médicos para escolherem e exercerem a profissão na APS. De acordo com os entrevistados, faltou enfoque para a APS na graduação que os fizesse ter uma experiência prática longitudinal na rede de saúde e obter, na formação acadêmica, uma visão abrangente do sistema básico de saúde e também sobre as variadas possibilidades de atuação na prática da atenção em saúde mental.

Em determinado momento específico da entrevista, o mais comum era ouvir dos médicos algumas experiências sobre outras abordagens em saúde, principalmente aquelas prestadas em emergências nos hospitais gerais. Esse, aliás, foi um discurso predominantemente repetido pelos profissionais que já obtiveram sua graduação há algum tempo.

[...] Experiência nenhuma. Isso aí eu queria deixar claro. Como você viu, falei várias coisas, mas no campo da Psiquiatria nem Psicologia, nada. Só no dia a dia mesmo, como clínico mesmo, um ou outro paciente solto. [...] Na minha experiência nesses hospitais que te falei já vi alguns pacientes em surtos, com crises de esquizofrenia, abstinência alcoólica, que são mais comuns, né? Ansiedade também, né? DNV - Distúrbio Neuro Vegetativo. (E06)

Em contrapartida, os que acabaram de graduar-se em Medicina fizeram questão de ilustrar que sua pouca experiência na área da saúde mental poderia estar atrelada ao baixo prestígio dado aos atuais currículos universitários sobre o tema.

[...] Acredito ter faltado um enfoque maior para essa área de atuação profissional no meu curso. Cheguei a fazer um breve estágio no PSF - dois meses - durante o curso, no qual observei a atuação dos profissionais e o funcionamento das unidades, porém ainda acho que foi pouco. (E04)
Alguns profissionais relataram ter certa insegurança e incompreensão com relação a alguns diagnósticos no campo da saúde mental. Ainda na ocasião foi comum ouvir dos profissionais uma carência de "capacitações" sobre os temas pertinentes à saúde mental.

[...] Eu, como médico, tenho às vezes dificuldade de dar um diagnóstico de síndrome do pânico, de uma depressão, então eu acho que as capacitações nessa área precisam ser mais específicas e ter uma linguagem mais acessivel [...] (E02)

\section{A dimensão dada ao tratamento psicofarmacológico}

Pode-se perceber que em sua grande maioria os profissionais não se sentem seguros para lidar com as situações de saúde mental, recorrendo, regularmente, aos encaminhamentos à Psiquiatria. Quando assim não o fazem, lançam mão, inúmeras vezes, de alguma prescrição psicofarmacológica.

[...] se eu acho que consigo resolver o problema de acordo com meus conhecimentos, eu prescrevo remédio... Aí quando eu estou vendo que não estou conseguindo ajudar o paciente, aí eu encaminho [...] (E07)

Vale destacar que houve um consenso entre os profissionais que a relação de referência/contrarreferência realizada com a especialidade de saúde mental e demais, no município, carecem de melhoria. Na verdade, alguns médicos foram até mais enfáticos na crítica a esse modelo municipal.

Com relação às maiores demandas surgidas na ESF tornou-se comum ouvir que as grandes queixas que chegam ao serviço dão conta de sintomas compatíveis com queixas psicossomáticas relacionadas a ansiedade, depressão, seguidas por quadros sintomáticos de dependência alcoólica.

Dos sete profissionais entrevistados, dois referenciaram que orientam seus pacientes a procurarem grupos de apoio. Os demais revelaram conhecer pouco ou quase nada sobre a dinâmica de funcionamento social das comunidades nas quais estão inseridos.

Dos sete entrevistados, quatro citam que uma demanda significativa encontrada em seus atendimentos tem como foco a questão do alcoolismo.

\section{[...] Alcoolismo eu encontro muito. (E05)}

\section{[...] O maior problema de saúde aqui nesta área é o alcoolismo. (E01)}

Com relação à dependência do álcool na APS vale destacar que o Regulamento do Sistema Único de Saúde (SUS) dedica 22 de seus 790 artigos ao Programa de Atenção Integral a Usuários de Álcool e outras Drogas, prevendo que a APS seja um dos principais componentes da atenção integral aos usuários de substâncias psicoativas. Trata-se, portanto, de uma reafirmação da agenda internacional de compromissos colocada, três décadas antes, aos pesquisadores, gestores e clínicos da APS $^{22}$.

O programa preconiza que a APS se volte para a detecção precoce de casos de uso nocivo e de dependência de substâncias e para 
outras práticas preventivas, educativas e terapêuticas. A lógica da redução de danos ${ }^{4} \mathrm{e}$ as técnicas de $\mathrm{IB}^{5}$ (intervenções breves) são mencionadas como forma de se alcançar o objetivo terapêutico de redução ou cessação do consumo, recomendando-se, também, o encaminhamento precoce de pacientes para intervenções mais específicas, inclusive a abordagem das complicações clínicas e/ou psiquiátricas. Um dos profissionais sinalizou que referencia seus pacientes etilistas para participarem de reuniões em um grupo de Alcoólicos Anônimos que funciona próximo à unidade de saúde.

Em outro registro levantado, cinco dos sete entrevistados citam as queixas de transtornos de ansiedade.

[...] O maior problema de saúde mental nesta área é o alcoolismo, em seguida são os transtornos de esquizofrenia e de ansiedade. (E01)

[...] eu vejo mais se apresentando aqui é assim é muita agitação e ansiedade. (E05)

[...] Tem a depressão normal, os distúrbios de ansiedade. (E04)

[...] Ansiedade então tem muito. [...] ansiedade é toda hora... (E06)

Foram citadas como condutas nesses dois casos, encaminhamentos ao serviço de Psiquiatria do município. Relatos sobre uma problematização mais ampliada acerca dessas questões não foram referidas.

Com relação aos transtornos psicóticos, dois médicos de unidades localizadas no interior do município salientaram ter em sua área de atuação pacientes com esquizofrenia. Os demais profissionais não fizeram menção a essa condição e disseram não "tratar" dos pacientes psicóticos ali na ESF.

A questão da demanda por repetição de receitas de psicotrópicos foi um fator que teve marcante presença em todos os discursos. Segundo alguns médicos, existe uma relação de extremo desconforto quando o médico não atende a uma solicitação dessas.

[...] às vezes você até dá um medicamento pra não criar problema, entendeu? (E04)

\footnotetext{
d No âmbito da Psicoterapia das adições e toxicomanias, a redução de danos, mais popularmente conhecida pela sigla RD, pode ser considerada um paradigma, uma abordagem ou uma perspectiva e é utilizada para proporcionar uma reflexão ampliada sobre a possibilidade de diminuir danos relacionados a alguma prática que cause ou possa causar danos. Valoriza e põe em ação estratégias de proteção, cuidado e autocuidado, possibilitando mudança de atitude frente a situações de vulnerabilidade.

e As IBs são intervenções que podem também complementar atividades assistenciais habituais e que são inseridas na rotina usual de atendimento, ocupando um tempo mínimo, utilizando recursos didáticos para obter rapidamente um maior nível de informação do paciente sobre seus problemas atuais, avaliando e eliciando a motivação para mudança, preparando-o para tomar decisões. Assim, por exemplo, um médico do Programa de Saúde da Família poderá incorporar na consulta de rotina um breve momento destinado à triagem para identificação de pacientes com PRUS (Problemas relacionados ao uso de substâncias), incluindo no seu esquema usual de seguimentos e monitorizações parte da consulta para aplicar a IB.
}

[...] Eu refaço as receitas que já vêm lá de Cachoeiras, que o paciente mostra que já faz uso de remédio controlado, aí eu repito às vezes a receita. (E06)

[...] Muitos dos que vêm aqui pra pegar a receita, você tenta conversar aí eles resistem dizendo não, mas o meu médico é outro e tal, eu acho essa prática bastante complicada. (E03)

De acordo com alguns estudos realizados de um modo geral, a demanda relativa à saúde mental mais frequente na realidade das ESF é a de pacientes que procuram a unidade para renovar a receita e continuar o tratamento. Outras demandas também são mencionadas, como uso de álcool e drogas e situações constatadas como sendo transtorno mental na área de cobertura da equipe. Contudo, a demanda pela renovação de receitas parece ser mais comum e mais alarmante ${ }^{23}$.

\section{A atenção psicossocial na Estratégia de Saúde da Família em conformidade com os aspectos da Reforma Psiquiátrica}

As concepções do processo saúde-doença mental expostas pelos sujeitos entrevistados atende predominantemente ao modelo clínico individual, organicista e biológico na maneira de conceber o transtorno mental, contrapondo-se ao modelo de atenção psicossocial, bem como à atual política de organização dos serviços de saúde na perspectiva da Reforma Psiquiátrica, onde a atenção básica deve ser realizada também e em conjunto com as unidades básicas de saúde.

A saúde mental ainda tem sido um desafio para os profissionais da ESF. Segundo dados da OMS, uma em cada quatro pessoas desenvolvem transtornos psíquicos em algum momento da vida. Em países desenvolvidos, $44 \%$ a $70 \%$ das pessoas não recebem tratamento adequado, enquanto nos países em desenvolvimento esse percentual pode chegar a $90 \%$, refletindo no impacto dos agravos em saúde mental na população e também na atenção básica, visto ser esse o único atendimento disponível em muitas localidades brasileiras ${ }^{6}$.

A partir dos avanços da Reforma Psiquiátrica, criou-se uma responsabilidade pelo delineamento de novos caminhos na assistência aos doentes mentais. A reforma propõe-se a romper gradativamente com o modelo centrado no hospital, a criar serviços territoriais abertos. Surge, então, a necessidade de articular saúde mental e ESF, trazendo mais uma demanda para os profissionais que atuam nessas unidades.

Sendo assim, um dos objetivos desta pesquisa foi avaliar como os profissionais entrevistados entendiam e miravam suas práticas para que a população atendida de fato pudesse experimentar um dos pressupostos da Reforma Psiquiátrica no Brasil.

Uma das questões disparadoras da entrevista trazia como temática de reflexão o conhecimento que os entrevistados possuíam sobre as ATs (atividades terapêuticas) desenvolvidas na comunidade. Ao formular a questão disparadora eram feitas menções ao fato de o entrevistado conhecer na comunidade 
movimentos sociais, grupos de terceira idade, ONGs, associação de moradores, grupos de autoajuda, grupos de idosos etc.

Após um detalhamento do conceito do que seriam as atividades terapêuticas foi comum perceber a falta de conhecimento dos entrevistados sobre a realização dessas atividades nas comunidades. Era comum ouvir relatos do tipo:

[...] Olha não tenho ouvido falar nisso não. Eu acho que na verdade a coisa ainda tá muito centrada no médico e no paciente. (E05)

As particularidades do território de abrangência das unidades também não foram citadas espontaneamente por nenhum entrevistado. Foi possível notar que existia por parte dos profissionais um desconhecimento sobre as características daqueles locais.

[...] Não. Até porque eu não sou daqui. Eu fico mais aqui no posto mesmo, entendeu? (E05)

Nenhum dos médicos entrevistados mora na localidade em que está sediada a unidade de saúde. Outro dado relevante é que três dos sete médicos entrevistados não moram na cidade onde foi realizado o estudo.

Esse entrave poderia ser minimizado caso as informações sobre a comunidade fossem partilhadas pelos agentes de saúde e equipe de saúde nos momentos de reunião de equipe. Porém esses espaços de reflexão são escassos e muitas vezes não são vivenciados pelos médicos.

O reconhecimento desse território é um passo básico para a caracterização da população e de seus problemas de saúde, bem como para avaliação do impacto dos serviços sobre os níveis de saúde dessa população ${ }^{24}$.

\section{DISCUSSÃO}

Após a análise dos resultados encontrados nas entrevistas com os médicos foi possível observar algumas características, dentre elas: a persistência de uma formação acadêmica fragmentada e basicamente hospitalar; a falta de educação permanente, voltada ao reconhecimento dos problemas da realidade local; a minimização de uma visão subjetiva das comunidades, seu território e suas relações; a minorização da importância do contexto que a relação familiar representa no perfil saúde-doença dos usuários.

Essas, aliás, são questões presentes em estudos recentes e que aqui se revelam na análise do contexto de implementação da estratégia em um campo de possibilidades e de limites para a consolidação do novo modelo de reordenamento da Atenção Primária.

Cumpre chamar atenção para o fato observado na prática desses profissionais que evidencia as consultas médicas na unidade como sua principal atividade, em detrimento de outras atribuições também sugeridas em sua atuação, como visitas domiciliares, participação em eventos comunitários, realização de palestras e diversas abordagens outras que buscam promover uma maior integração desse profissional com a comunidade.

Com relação às exigências surgidas na prática médica foi relatado por alguns entrevistados insegurança e incompreensão sobre o tema saúde mental.

Foram sinalizadas como principais demandas em saúde mental queixas de ansiedade, estresse, alcoolismo e depressão.

A questão da demanda por repetição de receitas de psicotrópicos foi um fator que teve presença marcante em todos os discursos. Segundo alguns médicos, essa, aliás, é uma condição muito angustiante para eles, pois apesar de terem um pensamento crítico com relação ao uso indiscriminado de psicotrópicos na contemporaneidade, eles se veem "forçados" a repetir receitas já prescritas por outros profissionais.

Chama a atenção o fato de nenhum dos entrevistados relatar ênfase na APS durante a graduação, nem receber incentivos e informações necessários para optar por esse campo de trabalho.

Como parte dos entrevistados era formada nos últimos cinco anos, percebe-se que, apesar dos esforços presentes, as escolas médicas persistem em não potencializar a prática médica extra-hospitalar, que necessita, obrigatoriamente, da interação entre o conhecimento médico sobre os processos de adoecimento e o conhecimento do paciente sobre sua vida, sem os quais não há possibilidade de desenvolvimento de um diagnóstico e de uma ação terapêutica consistente.

Para atuar na ESF e realizar um atendimento médico tecnicamente consistente, é necessária uma formação que amplie o campo de percepção clínica, sob o risco de se desenvolver uma atuação profissional superficial, ineficiente e de baixa resolutividade, dominada pela monotonia e repetitividade oriundas da pobreza fisiopatológica dos casos e da estreiteza do olhar médico.

Constata-se ainda uma tendência muito forte de se considerar o trabalho na APS como algo de menor valor e prestígio no meio acadêmico, quando comparado ao trabalho em outras especialidades médicas.

Conforme vimos no referencial teórico deste estudo, os médicos são bombardeados com informações do tipo que a depressão está para se tornar a segunda principal causa de incapacidade em todo o mundo, pois afeta de 5\% a $10 \%$ da população e é a terceira razão mais comum para consulta na atenção primária à saúde. Mas o que vemos no discurso dos médicos entrevistados é a necessidade candente de melhor compreensão desses processos de transtorno do humor em geral, de tristeza e ansiedade, para que possam dar um suporte mais adequado ao usuário. Dos sete entrevistados, nenhum relatou que métodos utiliza para identificar nos pacientes os critérios diagnósticos para tal mal-estar.

Vale trazer para reflexão a seguinte questão: Será que alguns diagnósticos de depressão realizados na ESF não poderiam estar 
mimetizados com sintomas de tristeza, desemprego, elaboração de um luto ou angústia, eventos esses intrínsecos à vida humana? Reconhecer, portanto, uma boa gama da subjetividade dos pacientes assistidos na ESF torna-se questão urgente para esses profissionais que lidam com o sofrimento humano. Nesse caso, fomentar espaços de reflexão sobre os processos de trabalho nas unidades é uma questão importantíssima a ser considerada.
Dessa maneira, é necessário assumir uma posição de médico da família e não simplesmente de um médico ambulatorial. Compreender, olhando para esses sujeitos, as relações que os atravessam (família, as relações de convivência, de trabalho, de moradia), as quais são fundamentais para que uma postura reducionista de medicalização da vida assuma novas formas e possibilidades outras.

\section{REFERÊNCIAS}

1. Escorel S, Giovanella L, Mendonça MHM, Senna MCM. O Programa Saúde da Família e a construção de um novo modelo para a atenção básica no Brasil. Rev Panam Salud Publica. 2007,21(2):164-76.

2. Brasil. Ministério da Saúde. Reforma Psiquiátrica e política de saúde mental no Brasil [Internet]. Brasília: Ministério da Saúde; 2005 [citado em 2012 ago 11]. Disponível em: http://www.saude.gov.br

3. Brasil. Lei no 8.080 , de 19 de setembro de 1990. Dispõe sobre as condições para a promoção, proteção e recuperação da saúde, a organização e o funcionamento dos serviços correspondentes e dá outras providências. Diário Oficial da União, Brasília, 20 de setembro de 1990, n. 182, p. 1805518059, seção I.

4. Brasil. Ministerio da Saúde. Política Nacional de Humanização: a humanização como eixo norteador das práticas de atenção e gestão em todas as instâncias do SUS [Internet]. Brasília: Ministério da Saúde; 2006 [acesso em 2012 ago 9]. Disponível em: http://dtr2004.saude.gov.br/susdeaz/instrumento/ arquivo/04_Cartilha_HumanizaSUS.pdf

5. Organização Mundial da Saúde. Classificação estatística internacional de doenças e problemas relacionados à saúde. 10. ed. São Paulo: Universidade de São Paulo; 1995.

6. Brasil. Ministério da Saúde. Secretaria de Atenção à Saúde. Saúde Mental e Atenção Básica: o vínculo e o diálogo necessários - Inclusão das ações de Saúde Mental na Atenção básica. Brasília: Ministério da Saúde; 2003. Circular Conjunta n. 01 e 03.

7. World Health Organization. What is the evidence on effectiveness of capacity building of primary health care professionals in the detection, management and outcome of depression? [Internet]. Copenhagen: WHO; 2004. [citado em citado em 2013 ago 19]. Disponível em: http://www.euro. who.int/document/e85243.pdf

8. Maragno L, Goldbaum M, Gianini RJ, Novaes HM, César CL. Prevalência de transtornos mentais comuns em populações atendidas pelo Programa Saúde da Família (QUALIS) no município de São Paulo, Brasil. Cad Saude Publica. 2006;22(8):1639-48. http://dx.doi.org/10.1590/S0102-311X2006000800012. PMid:16832535.

9. Instituto Brasileiro de Geografia e Estatística. Contagem populacional [Internet]. [citado em 2012 out 20]. Disponivel em: http://www.sidra.ibge. gov.br/bda/popul/default.asp?

10. Cruz Machado. Prefeitura Municipal. PMCM- Relatório anual [Internet] [citado em 2013 ago 19]. Disponível em: http//www.pmcm.org.br

11. Sistema de Informação de Atenção Básica. Relatórios de Atividades Municipais 2012. Brasília: SIAB; 2012.

12. Gomes R, Minayo MCS, Assis SG, Souza ER, Malaquias JV, Silva CFR, organizadores. Organização, processamento, análise e interpretação de dados: o desafio da triangulação. Avaliação por triangulação de métodos: abordagem de Programas Sociais. Rio de Janeiro: Fiocruz; 2010. p. 185-221.

13. Sistema de Informação de Atenção Básica. Relatórios de Atividades Municipais 2012-2013. Brasília: SIAB; 2013.

14. Minayo MCS, Assis SG, Souza ER, organizadores. Avaliação por triangulação de métodos: abordagem de programas sociais. Rio de Janeiro: Fiocruz; 2005. p. 39.

15. Minayo MCS. Introdução. In: Minayo MCS, Assis SG, Souza ER, organizadores. Avaliação por triangulação de métodos: abordagem de programas sociais. Rio de Janeiro: Fiocruz; 2010. p. 19-51.

16. Lira ARS. O desafio do Apoio Matricial em Saúde Mental feito às equipes de Saúde da Família em Aracajú. Rio de Janeiro: UFRJ/IPUB; 2007. (Cadernos IPUB. Saúde Mental na Atenção Básica, 24).

17. Brasil. Ministério da Saúde. Secretaria de Políticas de Saúde. A implantação da unidade de saúde da família. Brasília: Ministério da Saúde; 2000. (Cadernos de Atenção Básica. Programa de Saúde da Família. Caderno 1).

18. Merhy EE. A perda da dimensão cuidadora na produção da saúde: uma discussão do modelo assistencial e da intervenção no seu modo de trabalhar a assistência. In: Campos CR, Malta DC, Teixeira dos Reis A, Santos A, Merhy EE. Sistema Único de Saúde em Belo Horizonte - reescrevendo o público. Belo Horizonte: Xamã Vm Editora; 1998.

19. Silva IZQJ, Trad LAB. El trabajo en equipo del PSF: investigando la articulación técnica y la interacción entre los profesionales. Interface - Comunic., Saúde, Educ. 2005,9(16):25-38. http://dx.doi.org/10.1590/ S1414-32832005000100003.

20. Singly F. O nascimento do "indivíduo individualizado"e e seus efeitos na vida conjugal e familiar. In: Peixoto CE, Singly F, Cicchelli V, organizadores. Família e individualização. Rio de Janeiro: Editora FGV; 2000. p. 37-9.

21. Brasil. Ministério da Saúde. Programa de Saúde da Família: uma estratégia para a reorientação do modelo assistencial. Brasília: Ministério da Saúde; 2006.

22. Brasil. Ministério da Saúde. Departamento de Atenção Básica. Saúde da Família. Núcleo de Apoio à Saúde da Família (NASF) [Internet]. Brasília: Ministério da Saúde; 2004 [citado em 2009 jan 30]. Disponível em: http:// dtr2004.saude.gov.br/dab/nasf.php

23. Dimenstein M, Severo A, Brito M, Pimenta A, Medeiros V, Bezerra E. O apoio matricial em Unidades de Saúde da Família: experimentando inovações em saúde mental. Saúde Soc. 18(1):63-74, 2009. http://dx.doi. org/10.1590/S0104-12902009000100007.

24. Barcellos C. A saúde nos Sistemas de Informação Geográfica: apenas uma camada a mais? Caderno Prudentino de Geografia. 2003;25:29-43.

Recebido em: Out. 15, 2015 Aceito em: Nov. 09, 2015 
Anexo A. Roteiro semiestruturado
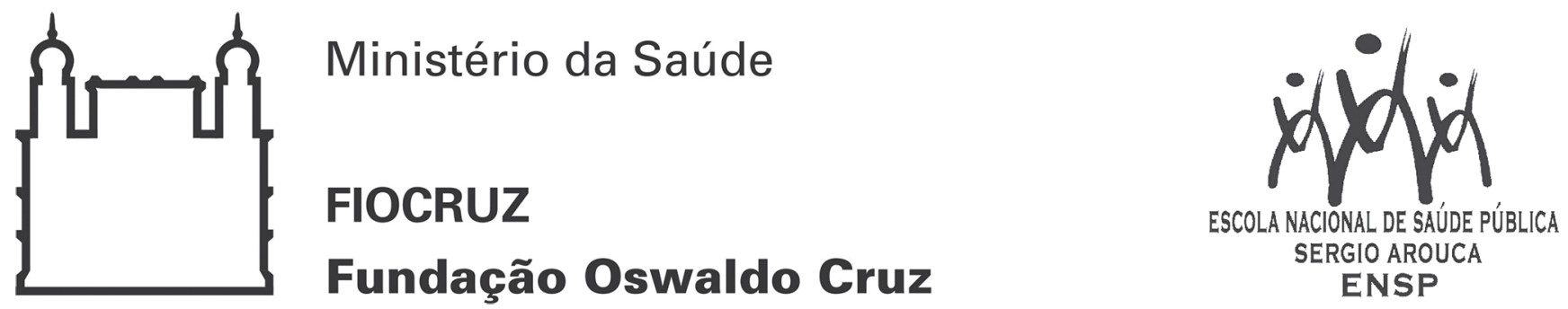

Estudo sobre práticas de cuidado em saúde mental na atenção primária: $\mathrm{O}$ caso de um município do interior do estado do Rio de Janeiro

Roteiro de questões disparadoras que será aplicado aos profissionais médicos da ESF.

1) Conte-me sobre sua trajetória profissional em relação à saúde mental...

2) Como você vê as questões da saúde mental no município?

2) Fale um pouco sobre sua conduta diante das demandas em saúde mental...

3) Como você avalia a rede de atenção em saúde metal aqui no município...

4) Quais as demandas em saúde mental que você observa com frequência em sua prática?

5) Você conhece alguma atividade terapêutica na comunidade? Fale sobre elas...

6) Suas considerações finais... 